University of New Hampshire

University of New Hampshire Scholars' Repository

Center for Coastal and Ocean Mapping

Center for Coastal and Ocean Mapping

$5-2008$

\title{
Environmental Response Management Application
}

Michele Jacobi

NOAA

Nancy E. Kinner

University of New Hampshire, Durham

Rob Braswell

University of New Hampshire, Durham

Kurt Schwehr

University of New Hampshire, Durham

Kimberly S. Newman

University of New Hampshire, Durham

See next page for additional authors

Follow this and additional works at: https://scholars.unh.edu/ccom

Part of the Oceanography and Atmospheric Sciences and Meteorology Commons, and the Oil, Gas, and Energy Commons

\section{Recommended Citation}

Michele Jacobi, Nancy E. Kinner, Bobby H. Braswell, Kurt D. Schwehr, Kimberly S. Newman, and Amy A. Merten (2008) ENVIRONMENTAL RESPONSE MANAGEMENT APPLICATION. International Oil Spill Conference Proceedings: May 2008, Vol. 2008, No. 1, pp. 881-885.

This Conference Proceeding is brought to you for free and open access by the Center for Coastal and Ocean Mapping at University of New Hampshire Scholars' Repository. It has been accepted for inclusion in Center for Coastal and Ocean Mapping by an authorized administrator of University of New Hampshire Scholars' Repository. For more information, please contact Scholarly.Communication@unh.edu. 


\section{Authors}

Michele Jacobi, Nancy E. Kinner, Rob Braswell, Kurt Schwehr, Kimberly S. Newman, and Amy A. Merten 


\title{
ENVIRONMENTAL RESPONSE MANAGEMENT APPLICATION
}

\author{
Michele Jacobi ${ }^{2}$, Nancy E. Kinner ${ }^{l}$, Bobby H. Braswell ${ }^{3}$, Kurt D. Schwehr ${ }^{4}$, Kimberly S. Newman $^{l}$, and Amy A. Merten ${ }^{2}$ \\ University of New Hampshire, Coastal Response Research Center \\ NOAA Office of Response and Restoration, CRRC \\ Complex Systems Research Center Environmental Data Systems Collaborative, University of New Hampshire \\ Center for Coastal \& Ocean Mapping, University of New Hampshire
}

\begin{abstract}
The Coastal Response Research Center (CRRC), a partnership between the University of New Hampshire (UNH) and NOAA's Office of Response and Restoration (ORR), is leading an effort to develop a data platform capable of interfacing both static and real-time data sets accessible simultaneously to a command post and assets in the field with an open source internet mapping server. The Environmental Response Management Application (ERMA $\left.{ }^{\mathrm{TM}}\right)$ is designed to give responders and decision makers ready access to geographically specific data useful during spill planning/drills, incident response, damage assessment and site restoration. In addition to oil spill and chemical release response, this website can be relevant to other environmental incidents and natural disasters, responses and regional planning efforts. The platform is easy to operate, without the assistance of Information Technology or Geographic Information Systems (GIS) specialists. It allows users to access individual data layer values, overlay relevant data sets, and zoom into segments of interest. The platform prototype is being developed specifically for Portsmouth Harbor and the Great Bay Estuary, NH. The prototype demonstrates the capabilities of an integrated data management platform and serves as the pilot for web-based GIS platforms in other regions.
\end{abstract}

\section{INTRODUCTION}

The evaluation of complex, real-world problems using specialized Geographic Information Systems (GIS) and open source software is operationally feasible due to widespread internet access, improvements in computer processing speeds, advances in geospatially-referenced data displays, and newly developed methods with which to interface disparate data sets. By using GIS, multiple data sets can be interconnected and displayed on a web-based map resulting in improved visualization of an area, and therefore better understanding of site conditions, potentially influencing factors, and overall incident information.

Ready access to data relevant to decision makers during all phases of spill planning, response and restoration must be balanced against the need to present information in a clear, concise and organized format that does not overwhelm the user. Such balance may be established by using web-based map software (e.g., MapServer and OpenLayers), which is seamlessly integrated with data layers that can easily be turned on/off to suit non-technical user needs. The data compilation package must be simple to operate and be able to "drill down" to access numerical data (i.e., metadata) and magnify segments of the geography.

To this end, the Coastal Response Research Center (CRRC), a joint partnership between the University of New Hampshire (UNH) and NOAA's Office of Response and Restoration (ORR), is developing the Environmental Response Management Application (ERMA ${ }^{\mathrm{TM}}$ ), formerly the Portsmouth Harbor Response Initiative, in collaboration with several UNH-NOAA centers and various NOAA offices and programs.

UNH and NOAA, in several joint partnerships, collaborate in research centers focused on:

- Spill response and restoration-CRRC,

- Coastal and ocean mapping - Joint Hydrographic Center (JHC)

- Coastal environmental technologies - Cooperative Institute for Coastal and Estuarine Environmental Technology (CICEET),

- Ocean observing - Joint Center for Ocean Observing Technology (JCOOT); Center for Coastal Ocean Observing and Analysis (COOA), and

- Environmental database management - Earth Systems Data Collaborative (ESDC).

These UNH-NOAA centers, along with NOAA's ORR, nowCOAST, NE Regional Coastal Program (RCP), Center for Sponsored Coastal Ocean Research (CSCOR), and Marine Modeling and Analysis Program (MMAP), are developing a prototype webbased platform that may be used during spill planning, spill drill exercises, incident response, damage assessment and restoration, as well as other environmental incidents and natural disasters or regional planning efforts. The prototype, being developed for spill response in Portsmouth Harbor and Great Bay Estuary, NH, demonstrates the capabilities of an integrated data management platform and serves as the pilot for web-based GIS platforms in other regions.

During a typical spill scenario, physical, chemical, and biological information can be integrated to assist decision making for response efforts. Spatially available electronic data, compiled by ERMA $^{\mathrm{TM}}$, include:

- Real-time weather and forecasts; water elevations;

- Environmental sensitivity and vulnerability index maps; 
- Real-time surface current directions and velocities, as well as the potential for predictions of those variables 24 to 48 hours in advance using integrated ocean observing systems (IOOS)

- Modeled spill trajectories and their associated uncertainties;

- Real-time tracking of vessels; critical utility locations (e.g., water intakes);

- Navigational charts;

- Bathymetry and sidescan surveys;

- Existing restoration sites;

- Water quality and sediment data; and

- Location of marine sanctuaries and estuarine research reserves, and socio-economically important areas (e.g., beaches, commercial fisheries) and natural resource information (e.g., spawning seasons, protected species).

\section{BACKGROUND}

ERMA $^{\mathrm{TM}}$ is the outcome of three independent initiatives brought together and led by the CRRC (www.crrc.unh.edu) (Figure 1). At the heart of ERMA ${ }^{\mathrm{TM}}$ is the UNH-NOAA Environmental Data Collaborative platform developed by the NOAA funded Earth Systems Data Collaborative (www.datacollaborative.unh.edu). The data collaborative integrates geo-spatial, regional-scale data and real-time and static data sets with suitable mapping capabilities, resulting in high-impact', high-resolution, visualization output. Figure 2 illustrates the platform concept in which data from a variety of sources (e.g., federal, state, local) are grouped and organized into a functional database which can be integrated to provide its users invaluable products, such as integrated GIS displays of complex, real-time conditions.

In September 2006, CRRC and NOAA ORR hosted a workshop entitled "Innovative Coastal Modeling for Decision Support: Integrating Physical, Biological and Toxicological Models" at UNH. Participants included approximately 35 individuals from NOAA, state and other federal and international entities, academia, and the private sector. The goal of the workshop was to identify critical modeling interactions and data needs that might improve decision making during environmental spills. The importance of the "response continuum" - from initial response, in the hours following an incident, to restoration and recovery, years to decades later (Figure 3) - was emphasized. The impact of multiple resources and stakeholders, complex data needs, and information management challenges on overall response times and decision making in turn affects recovery endpoints years later. Central to the workshop was the question of whether state-of-the-art technologies can be leveraged to speed the time from the initial release decisions to recovery. ERMA ${ }^{\mathrm{TM}}$ was a direct outgrowth of this workshop.

Subsequent to the workshop, the UNH-NOAA centers worked together to demonstrate how their respective data sets and capabilities could be synthesized to support spill response decision making - specifically looking toward applying the data collaborative (platform) technology to improve response capabilities and information management, facilitating the decision making process. Spurred in part by NOAA's focus on a unified, multidisciplinary approach to achieving a better understanding of our environment (the "One NOAA" focus), the centers began developing the data collaborative technology for the Portsmouth Harbor region as a prototype application and data management architecture. As part of the process, the types of information needed and potential data sources from within the UNH-NOAA centers, state and federal agencies and the private sector were identified. Critical information and resource data categories included:

- Base/Background data

- Imagery

- Nautical charts
- Infrastructure, including oil and gas pipeline and platforms

- Jurisdictional boundaries

- Response

- Response assets

- Over flights

- Trajectories

- Shoreline Cleanup and Assessment Team (SCAT) output

- Environmental

- Indices - habitats, socioeconomic, shoreline

- Bioresource - habitat, trust species

- Contaminant(s)

- Observations

- Buoys

- nowCOAST

- NEXRAD

Figure 4 illustrates critical components to developing better informed response/recovery/restoration options.

\section{ERMATM PROTOTYPE}

Portsmouth, $\mathrm{NH}$, was chosen for the prototype because of: its proximity to UNH; its diverse shoreline development (e.g., industry, residential, protected habitats, tourist/recreational use); and the active partnership among New Hampshire and Maine (the two states abutting the harbor) response agencies, industry, and non-governmental organizations (NGOs). Other important characteristics of this area include routine shipments of oil and chemicals in the harbor and Piscataqua River and the presence of the Great Bay National Estuarine Research Reserve (NERR), Great Bay National Wildlife Refuge (NWR), and several other important wildlife management areas (e.g., Adams Point WMA, Bellamy River WMA). Because of its base in Portsmouth, the demonstration project was able to take advantage of the available resources, abundant data, and expertise that exists as a result of the UNH-NOAA partnerships.

The web-based platform prototype centers on the principle that diverse data sets can be displayed on a single map to allow for better visualization of the complex nature of an environmental incident, such as an oil spill (Figure 5). By prudently combining the data the full scope of an incident and the level of interaction can be seen. The integrated data layers can be turned on/off to produce a dynamic map display of the complex conditions in the spill area. The web-based nature of the platform is critical as it allows for the integration and synthesis of various types of information, provides a common operational picture for all individuals involved in an incident, improves communication and coordination among responders and stakeholders, and provides resource managers with the information necessary to make faster and better informed decisions. The web-based GIS platform, developed specifically for environmental response activities, packages the data in a welldesigned management, visualization, analysis, and communication tool. It is designed to be secure, easily accessible from field or command post locations, user friendly, quick to display a variety of mapped data, and provide simple data update and download capabilities.

The Portsmouth prototype uses open source software and can be programmed to meet individual user needs. The interface, which is similar to Google Maps, is easy to manipulate and provides the base imagery for the prototype platform. The resulting maps, display real-time observations and monitoring data, as well as provide active links to data sets, documents, websites, and field response data and photos. The prototype is a valuable communications tool for spill drills, planning, response, assessment, and restoration activities. A flow diagram of the ERMA ${ }^{\mathrm{TM}}$ platform from end user to data set, and the reverse, is provided in Figure 6. 


\section{PORTSMOUTH HARBOR STAKEHOLDERS MEETING}

On June 27, 2007, CRRC brought together regional organizations responsible for emergency response to participate in the initial prototype demonstration and discussion of the web-based GIS platform developed to improve decision support for planning, preparation and response to oil spills in the Portsmouth, NH region. Participants included representatives from New Hampshire and Maine response agencies, United States Coast Guard, US Environmental Protection Agency, US Navy, NOAA, regional associations and planners, the Nature Conservancy, UNH, and private sector organizations, including the Piscataqua River Cooperative and Public Service of New Hampshire. The goal of the meeting was to demonstrate potential capabilities and functionality of the platform and to gather input from prospective users. By involving regulators, responders, planners, and other stakeholders early in the project development, the design team hoped to ensure its practical application and function and fine tune platform capabilities based on user groups needs.

During the meeting, the ERMA ${ }^{\mathrm{TM}}$ development team demonstrated prototype capabilities in hypothetical spill scenarios for Portsmouth Harbor, the Piscataqua River, and Great Bay Estuary (Figure 7). The ERMA ${ }^{\mathrm{TM}}$ team illustrated how a base map or aerial photograph becomes a dynamic visualization and communication tool when various data, such as bathymetry, ship locations and ship traffic routes from the Marine Automatic Identification System are overlaid (Figure 8). In the event of an actual incident, the platform could provide detailed output - web-based maps of chart data and live links to source data - on potential submerged obstacles, vessels having traveled through the region, and specific vessel routes to the command post and designated responders in the field. The Great Bay Estuary begins at the mouth of the Piscataqua River and is a tidal estuary bordered by the Great Bay NERR, Great Bay NWR, and several wildlife management areas. With data for a hypothetical incident in the bay, the development team led participants through an application of the platform. A hypothetical trajectory of the spill (using the General NOAA Operational Modeling Environment (GNOME) and generated by NOAA ORR), relevant regional environmental sensitivity and vulnerability index maps, and maps and classifications were shown. The protected marine areas in the region and the results of a hypothetical SCAT assessment - field photo displays, field sheets, and SCAT maps and diagrams - were also exhibited (Figure 9). A second hypothetical scenario was staged near Seavey Island, located in Portsmouth Harbor near the mouth of the Piscataqua River. Portsmouth Harbor and the Piscataqua River are regular routes for oil and chemical shipments into the region. The ERMA ${ }^{\mathrm{TM}}$ team showed participants the spill trajectory map of the mock incident, the open responder chart for the area, regional ship traffic, current weather observations from buoys, and the relevant environmental contaminant data (Figure 10).

Participant feedback was very positive and new ideas and potential avenues of development were generated from the overall discussions. Participant feedback included thoughts on potential application (e.g., spill, natural disaster, and security response, spill drill exercises, restoration planning), overall construction and maintenance (e.g., system and data security, management, sustainability), and additional data needs (e.g., hazard data sets such as Material Safety Data Sheets, response equipment locations and staging areas, land use data). Questions and comments posed by meeting participants and those from subsequent meetings with stakeholders are being incorporated by the ERMA ${ }^{\mathrm{TM}}$ development team.

A technical working group of stakeholders was formed consisting of representatives from CCOM, ESDC, Fish and Wildlife Service, Gulf of Maine Ocean Observing System (GOMOOS), Maine Department of Environmental Protection, National Weather Service, the Nature Conservancy, NH Department of Environ- mental Safety, NH Division of Emergency Services, NH Fish and Game Department, NOAA ORR, nowCOAST, Portsmouth Naval Shipyard, Portsmouth River Cooperative, UNH Research Computing Center (RCC), U.S. Coast Guard, and Region I U.S. EPA. This group was later expanded to include other interested technical advisors from the State of FL and response consultants. This group is further refining user needs and data sets that will be part of the platform tool. In addition to content development, the working group focused on potential technical challenges, such as best methods for uploading data, secure access of materials, site stability and speed, as well as the best means for integrating the site within a response command post.

ERMA $^{\mathrm{TM}}$ supports NOAA's mission and national priorities of hazard resilient coastal communities, integrated ecosystem assessments, integrated water resource services, and outreach and communications. The many NOAA and regional contributors in the ERMA $^{\mathrm{TM}}$ initiative exemplify the CRRC's and NOAA's emphasis on blending national and regional priorities. This initiative also demonstrates CRRC's strategic partnerships, the application of its research results, improved preparedness and response, and the protection of coastal environments and communities.

ERMA $^{\mathrm{TM}}$ will be launched as a fully integrated prototype in March 2008. Once fully implemented, the ERMA ${ }^{\mathrm{TM}}$ platform prototype will support spill preparedness, aid in spill drill exercises, assist in the coordination of response efforts, define the extent of potential impacts, and aid in recovery, assessment, recovery, and restoration phases following a spill incident in the Portsmouth Harbor region. The ERMA ${ }^{\mathrm{TM}}$ team, CRRC, and NOAA are planning the first full application of the prototype platform during a spill drill in Portsmouth Harbor in June 2008. The CRRC and NOAA ORR team are currently planning to adapt ERMA ${ }^{\mathrm{TM}}$ to other regions throughout the United States.

\section{FIGURE 1. DIAGRAM OF SYNTHESIS OF EFFORTS THAT LED TO ERMA ${ }^{\text {TM }}$}

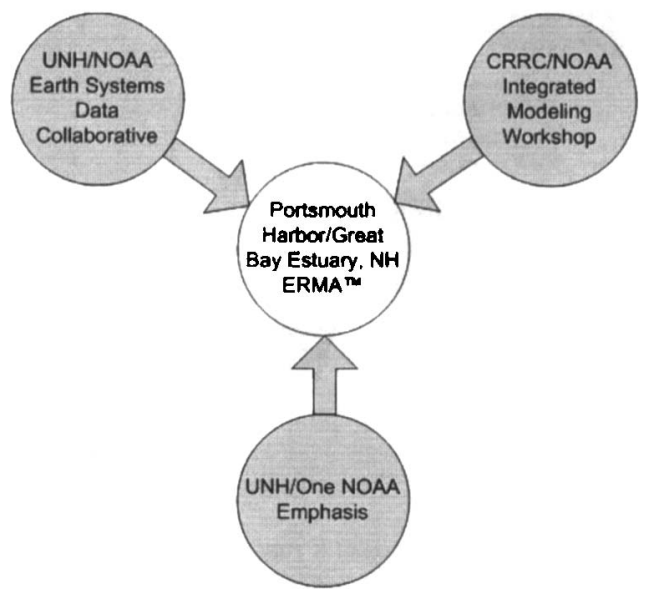


FIGURE 2. DIAGRAM OF THE PLATFORM CONCEPT ON WHICH ERMA ${ }^{T M}$ WAS DEVELOPED.

Platform Concept

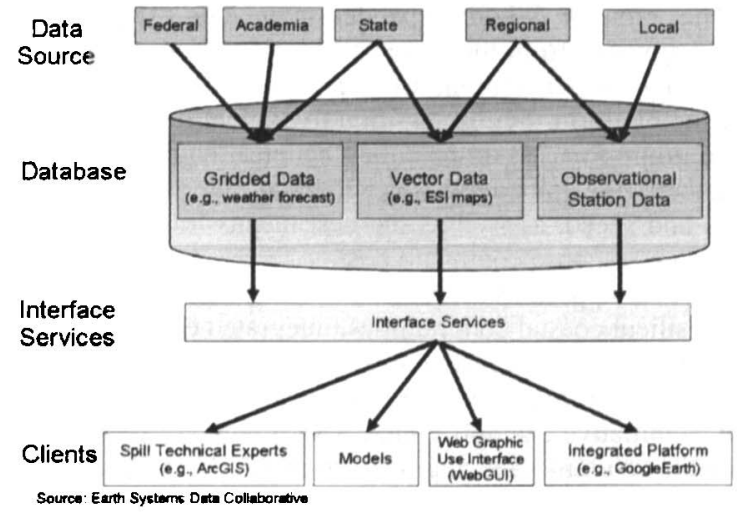

FIGURE 3. FLOW DIAGRAM OF SPILL RESPONSE PROCESS FROM INITIAL INCIDENT TO ENVIRONMENTAL ENDPOINT.

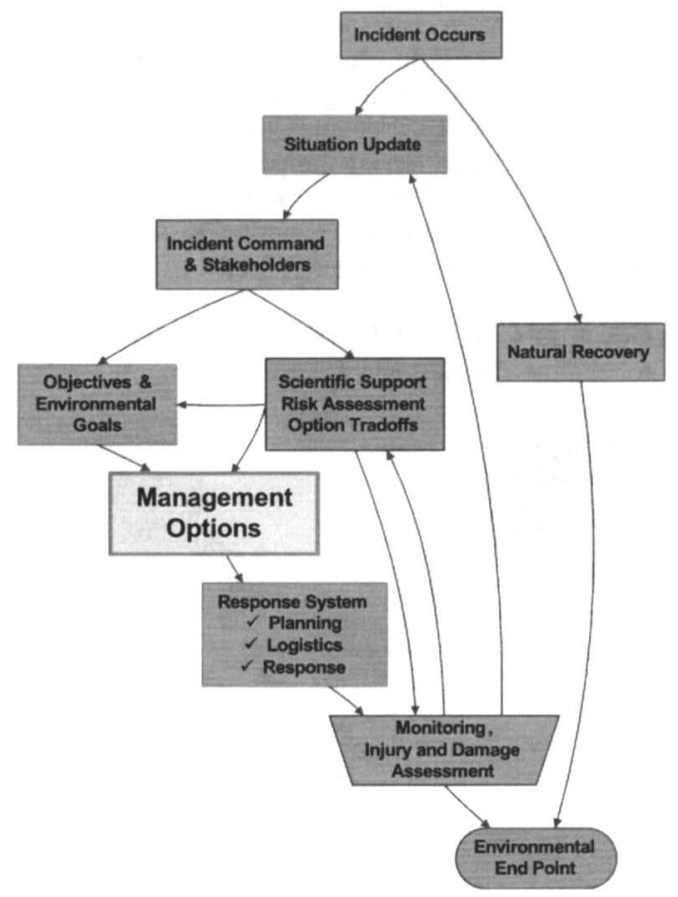

Source: Based on the discussions of a subgroup from the Center's "Innovative Coastal Modeling for Decision Support: Integrating Physical, Biological and Toxicological Models" workshop. This group, consisting of Center CoDirectors, workshop organizing committee members and participants has authored an article accepted for publication in EOS.
FIGURE 4. CRITICAL COMPONENTS IN THE DEVELOPMENT OF BETTER INFORMED MANAGEMENT OPTIONS BASED ON INTEGRATED MODELING.

Integrated Modeling

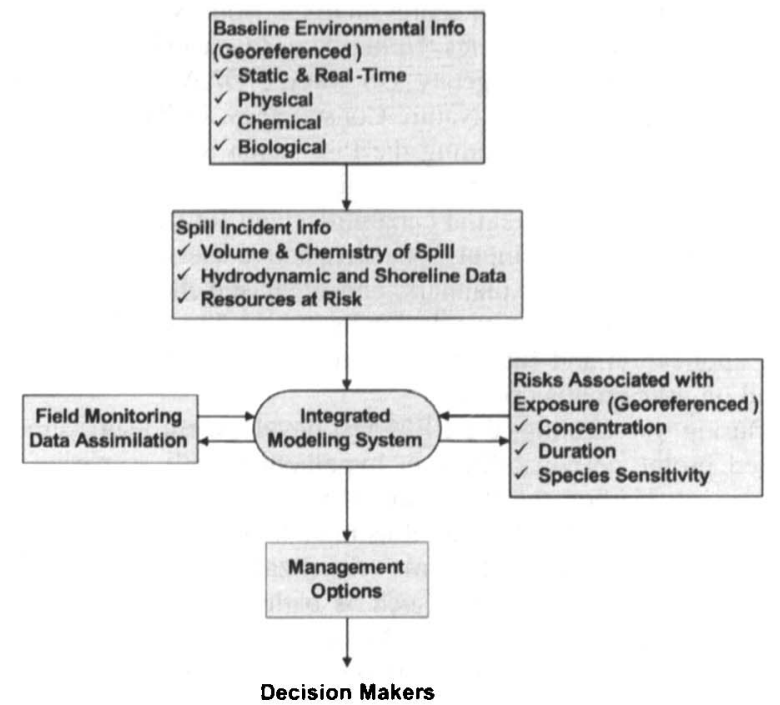

Source: Based on the discussions of a subgroup from the Center's "Innovative Coastal Modeling for Decision Support: Integrating Physical, Biological and Toxicological Models" workshop. This group, consisting of Center CoDirectors, workshop organizing committee members and participants has authored an article accepted for publication in EOS.

FIGURE 5. CONCEPT OF ERMATM : CRITICAL DATA SETS ARE OVERLAID TO PRODUCE A DYNAMIC MAP DISPLAY WITH LAYERS THAT CAN BE TURNED ON/OFF TO SUIT USER NEEDS.

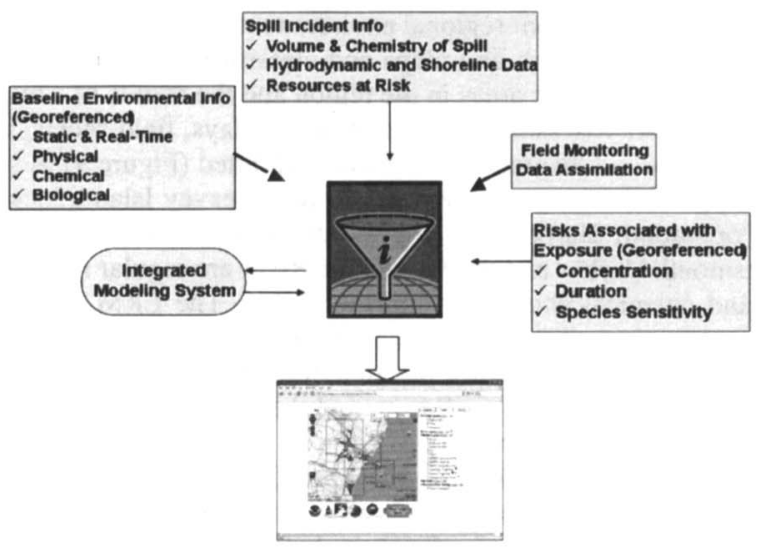


FIGURE 6. FLOW DIAGRAM OF THE ERMATM PLATFORM PROCESS.

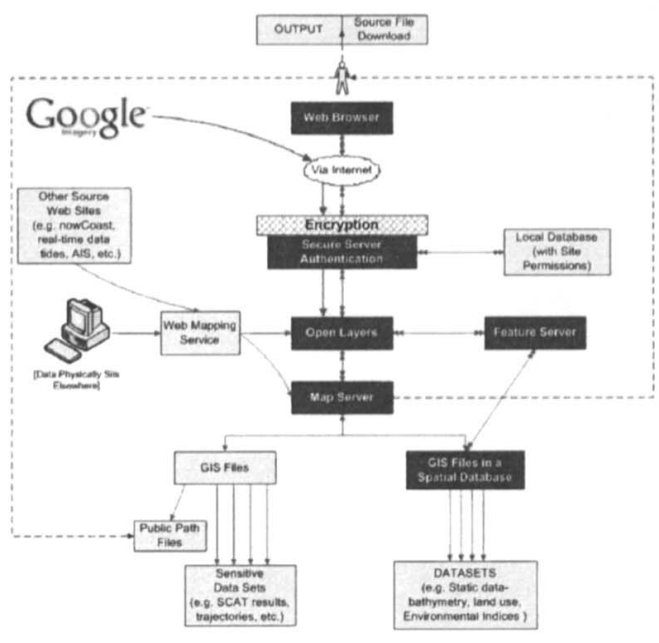

FIGURE 7. ERMATM OUTPUT MAP OF PORTSMOUTH HARBOR REGION, INCLUDING THE PISCATAQUA RIVER AND GREAT BAY ESTUARY.

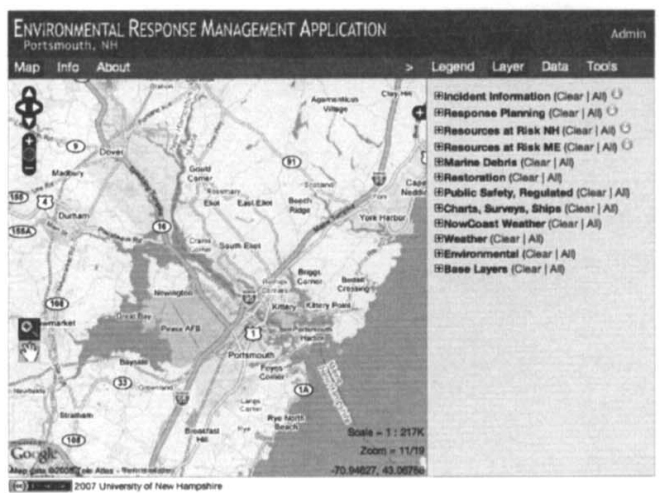

FIGURE 8. ERMATM OUTPUT SHOWING BATHYMETRY DATA, SHIP LOCATIONS AND SHIP TRAFFIC IN A SEGMENT OF THE PISCATAQUA RIVER.

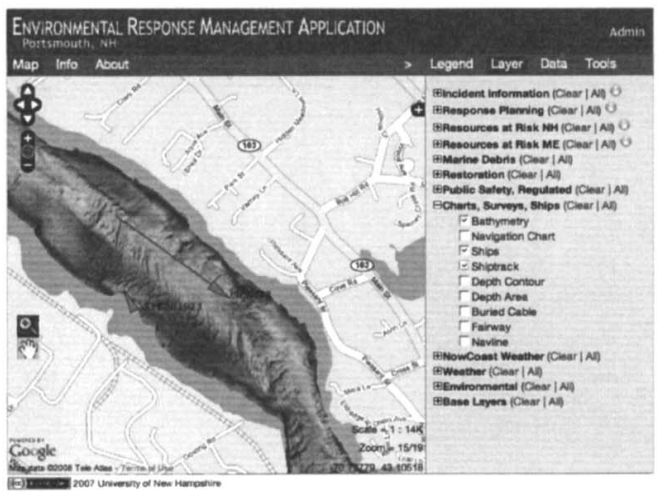

FIGURE 9. ERMATM OUTPUT SHOWING HYPOTHETICAL SPILL TRAJECTORY IN THE GREAT BAY ESTUARY WITH ESI SHORELINES, BIRD NESTING SITES, AND SCAT SAMPLING LOCATIONS AND MARINE DEBRIS FIELD PHOTO.

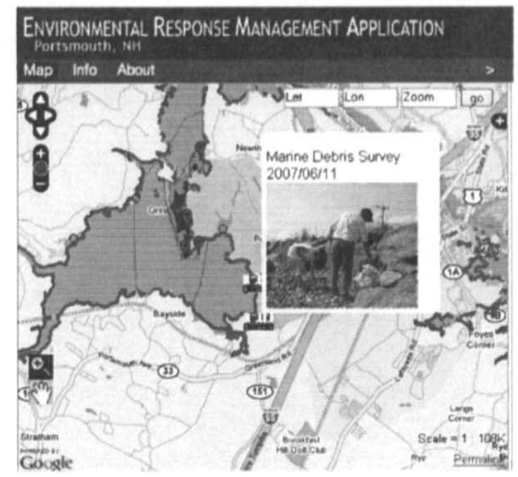

FIGURE 10. ERMATM OUTPUT SHOWING HYPOTHETICAL SPILL TRAJECTORY NEAR SEAVEY ISLAND IN PORTSMOUTH HARBOR, REGIONAL SHIP TRAFFIC, CURRENT TIDE OBSERVATIONS FROM BUOYS, AND CONTAMINANT SAMPLING POINT LOCATIONS.

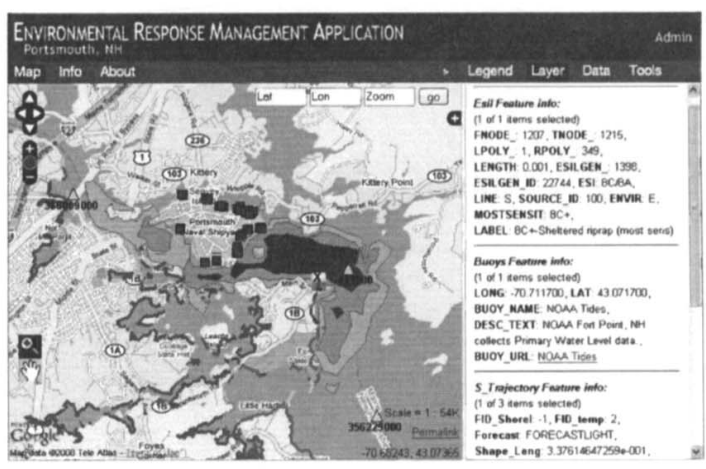


